\title{
University hospitals in Turkey: Structural crisis in financing or consequence of mismanagement?
}

\author{
A. Murat Tuncer ${ }^{1}$, Mehtap Tatar*2, İsmet Șahin ${ }^{3}$ \\ ${ }^{1}$ International Prevention Research Institute, Turkey \\ ${ }^{2}$ Polar Health Economics and Policy, Turkey \\ ${ }^{3}$ Hacettepe University, Turkey
}

Received: April 4, 2017

DOI: $10.5430 /$ jha.v6n4p52
Accepted: July 16, 2017

URL: https://doi.org/10.5430/jha.v6n4p52

\begin{abstract}
University hospitals in Turkey have a prominent role especially in treatment of complex cases and research. However, despite their indispensible place in the health care system, their financial status has long been on the agendas of the Turkish health policy-makers and is seen as a major threat to the financial sustainability of the whole system. It has been reported that the total debt of university hospitals has reached to 4.5 billion TRY ( 1.1 billion $€$ ) in 2016 . This debt is to the third parties that provide medical devices, pharmaceuticals or services to these hospitals. There is also an increasing trend in university hospital debts calling for an urgent attention from the government. This article aims at exploring the financial status of university hospitals and showing that with a new management approach focusing on efficiency and effectiveness measures, the problem could be overcome. The example from Hacettepe University Hospital showed that a problem solving management approach and a reformist vision between December 2011-January 2016 has resulted in major improvements in the financial status of the hospital. The debts of the hospital were stabilized in this period by policies focusing on increasing number of patients and procedures, by decreasing the cost of purchasing goods and materials and by following the Social Security Institution's (SSI) payment procedures. Starting from January 2016 a new management took the office and abandoned the measures taken by the previous administration. This led to an increase in hospital debts again. The article concluded that despite a volatile reimbursement environment, good management practices could help university hospitals to sustain their financial status.
\end{abstract}

Key Words: Hospital management, University hospitals, Turkey

\section{INTRODUCTION}

Turkey has embarked on a radical health care reform process in 2003 to improve a highly fragmented, complex, unequal, unresponsive health system with a questionable quality. After a decade, the old system was transformed into a responsive, comprehensive and competitive system with better quality. Major changes were adapted both in the financing and provision sides of health care services. In the financing side, a universal health insurance system was introduced, merging the old financing schemes with different rules and benefits packages under the Social Security Institution (SSI) and a sole purchaser of health care was created. Currently $95 \%$ of the Turkish population is covered by this scheme and enjoy a comprehensive health benefits package. The monopsonic power of the SSI makes the institution an important player in health policy together with the Ministry of Health $(\mathrm{MoH})$. In the provision side, first, the majority of public hospitals were merged under the $\mathrm{MoH}$. Second, as a result of the purchasing

\footnotetext{
*Correspondence: Mehtap Tatar, Prof., Dr.; Email: mehtap.tatar@polarsaglik.com; Address: Polar Health Economics and Policy, Dumlupınar Bulvarı No 266, Tepe Prime C Blok No 63, Çankaya, Ankara, Turkey.
} 
policies of the SSI, number of private hospitals and health care centers increased dramatically.

These policies had considerable impact on utilization of health care services, on health indicators and also on satisfaction from health care services. Introduction of a universal coverage scheme, equalizing health care benefits for everyone, purchasing health care services both from the public and private sector and several other new initiatives have increased the number of visits per person to a health care facility markedly (from 3.1 in 2002 to 8.4 in 2015). ${ }^{[1]}$ Satisfaction from health care services has also increased after the reforms, indicating public approval of the new arrangements (from $40 \%$ in 2003 to $71 \%$ in 2014) ${ }^{[1]}$ The transformation in overall health indicators after 2003 is also remarkable. Although some of these improvements can be attributed to parallel improvements in socio-economic indicators as well, the reforms have also made a clear contribution to the decrease in infant mortality rate (7.6 in thousands in 2015), maternal mortality rate (14.7 in 100,000 live births) and increase in life expectancy (from 72.5 in 2002 to 78 in 2015). The Turkish health care reforms and its contribution to the health status of the Turkish population is discussed elsewhere ${ }^{[2-5]}$ and is not the focus of this article. This article aims at discussing the place of university hospitals in the new Turkish health care system and their financial status with an example from a university hospital in Turkey. The example from a renowned Turkish university hospital will show how new approaches and good administration of a hospital can change and improve the financial indicators of a hospital even in a volatile environment.

\section{ROLE OF UNIVERSITY HOSPITALS IN THE TRANSFORMED TURKISH HEALTH CARE SYSTEM}

There are three tiers in the Turkish health care system as primary, secondary and tertiary care. The primary care is totally under the control of the $\mathrm{MoH}$ and is comprised of family practitioners and family health centers. The secondary care consists of hospitals both in the private and public sector. There are two types of hospitals at tertiary level: $\mathrm{MoH}$ Research and Education hospitals and University hospitals. The former only provides specialty training, in other words, doctors specialize in medical branches after graduating from a medical faculty whereas the latter provides specialty and medical training at the same time. Both hospitals also have research activities as well. University hospitals are attached directly to the university and to the Higher Education Council. The distribution of beds among hospitals is displayed in Figure 1.

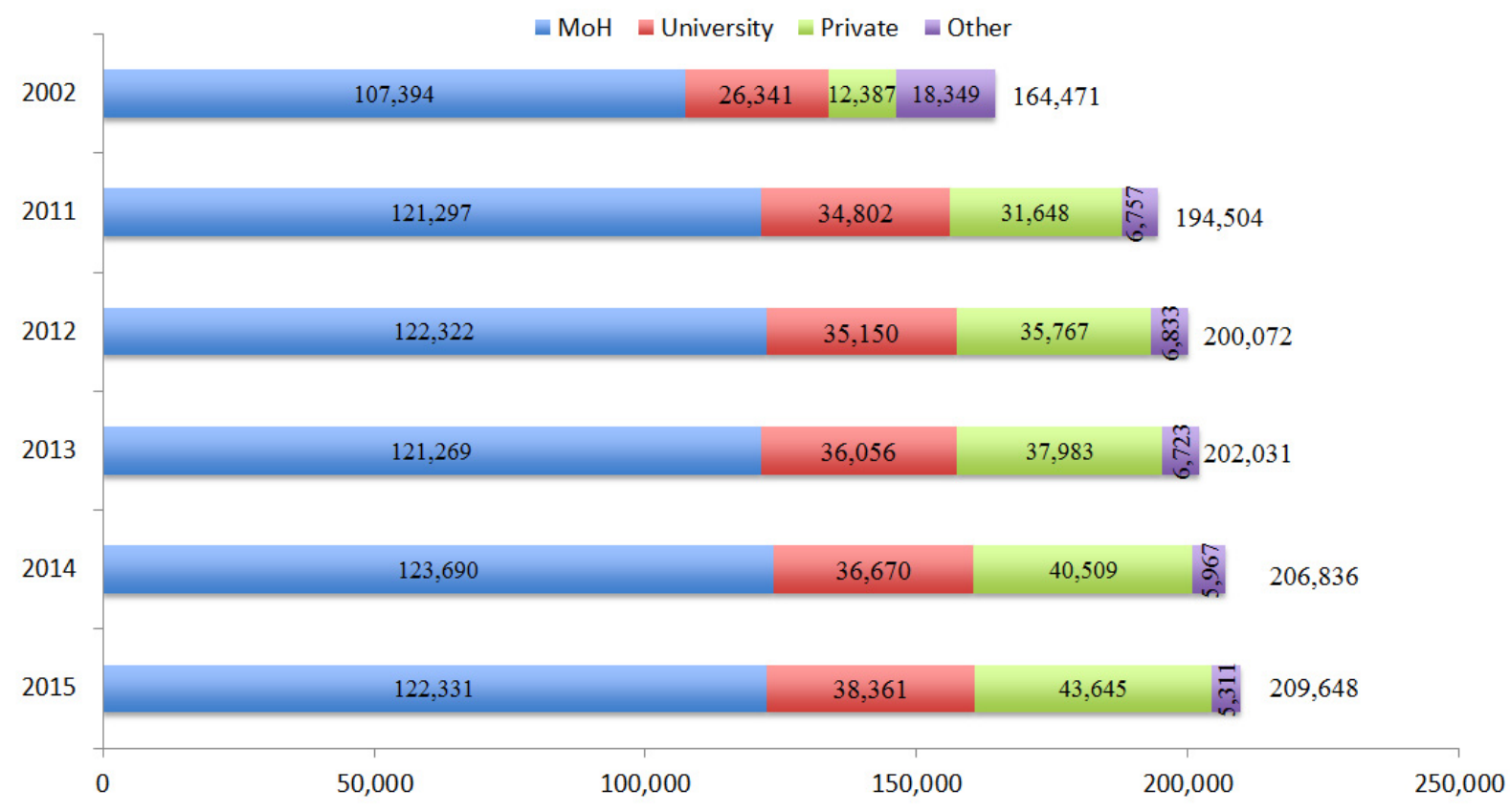

Figure 1. Number of hospital beds, Turkey ${ }^{[1]}$

Turkey has a social security based system and both employers and employees contribute to the financing of health care services. The SSI purchases health care services from health care providers both in the private and public sector. The deficits of the institution, both from the pension scheme and general health insurance scheme are subsidized form general 
government funds. There are co-payments at different lev- based on specific disease classifications (chronic diseases, els and there are also exemptions from co-payments mainly cancer etc.). Figure 2 summarizes the outlook of the current health care financing system of Turkey.

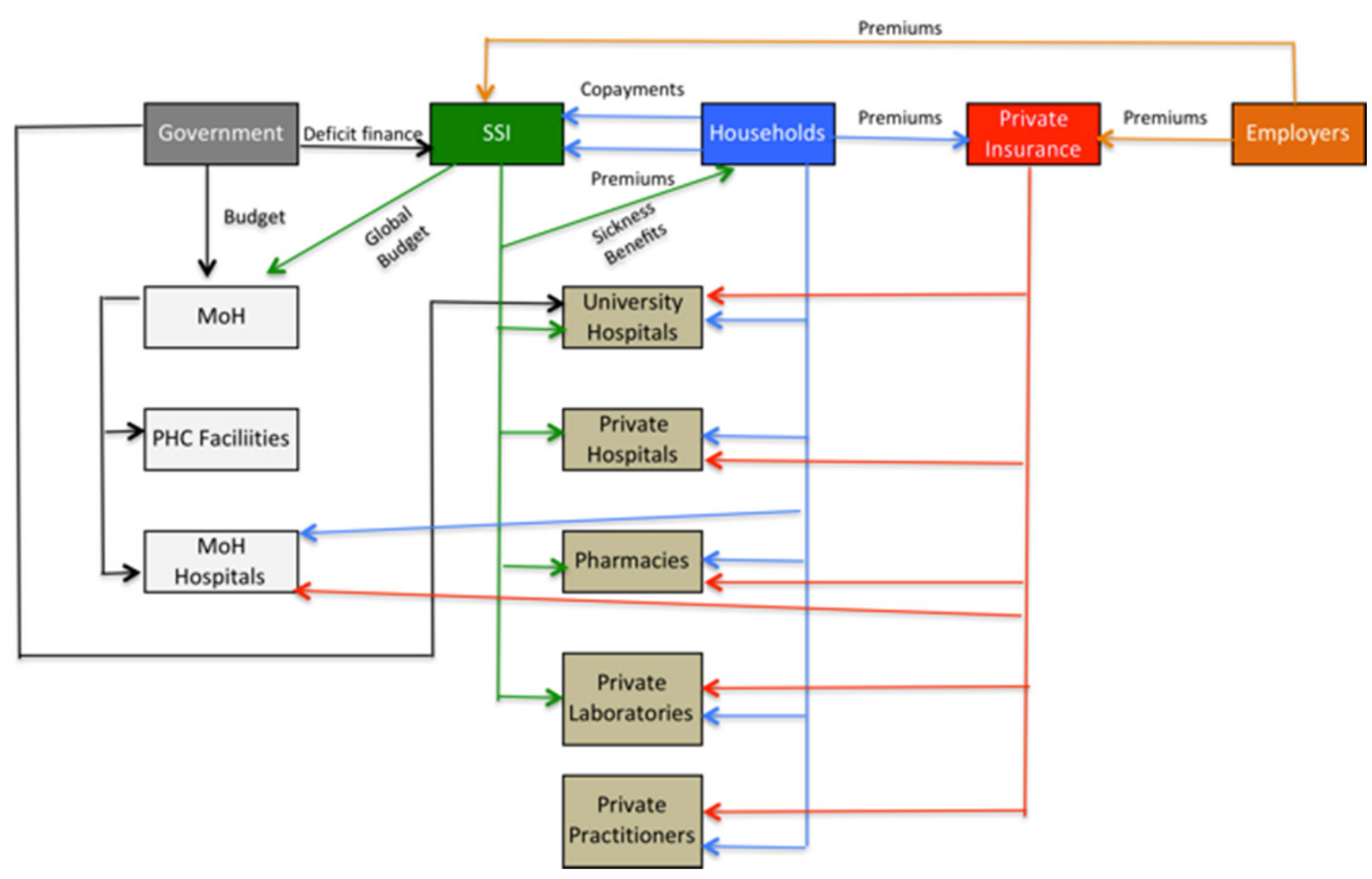

Figure 2. Flow of funds in the Turkish health care system

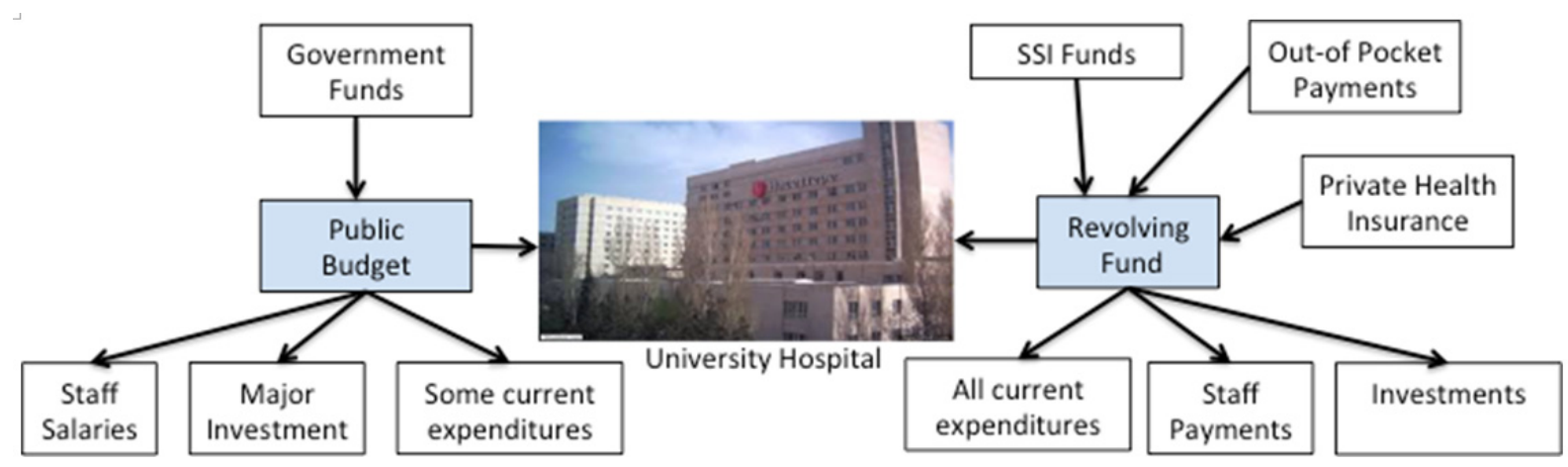

Figure 3. University hospitals' flow of funds: Turkey

As can be seen in Figure 2, university hospitals receive funds from the SSI, households, private insurance companies and general government. There is a dual budget that can be used for different purposes in each university hospital. Government funds are allocated to each university hospital's public budget according to its number and specifics of staff, approved investment programs and other current expenditures based on previous year's spending. There is also a revolving fund in each hospital and all payments both from the public and private funds for the services provided by the facility are deposited in this budget. This is the main budget that a hospital uses to provide health care services and to run the hospital. Purchasing new equipment, drugs, medical devices, all other materials and making extra payments to the 
staff based on their performance are made out of this budget. The flow of funds for university hospitals is displayed in Figure 3.

The SSI pays for the health care services provided by university hospitals based on the Health Implementation Guide (HIG) covering the rules of payment and prices of all health care services. The SSI pays hospitals both on a fee for service base and also on package price. Some services are determined under package payment system and the SSI pays a fixed price for health services under this category. This is used both for outpatient and inpatient services. The payment under this category covers expenditures for all services provided. As the SSI does not cover the difference between the HIG price and actual expenditures, the hospital has an incentive to contain costs within the limits of the package payment. If the hospital's actual cost is over the limit of the package payment, then this is recorded as a deficit in the financial balance of the hospital. The vice versa is also true. In other words, if the hospital's actual cost is lower than the package price then the difference is recorded as a positive contribution to the financial balance. There are also services classified under the fee-for-service payment system by the SSI.

University hospitals, by definition, are responsible for research, training and treatment of complex cases. Despite a number of achievements in the health care transformation process, a referral system where patients are referred from primary care to secondary and then tertiary care could not be introduced yet. Currently, a patient can visit a university hospital even for a simple disease that can be treated at the primary level by a family practitioner. This raises questions about the role of university hospitals in the Turkish health care system.

\section{FINANCIAL CRISIS OF UNIVERSITY HOSPI-} TALS

The financial status of university hospitals has long been on the agendas of the Turkish health policy makers. The burden of the deficits on the public sources is a major concern and is accepted as a threat to the sustainability of health care financing. It has been reported that the total debt of university hospitals has reached to 4.5 billion TRY (1.1 billion $€$ ) in 2016. This debt is mainly to the suppliers of health care products such as medical devices and pharmaceuticals. The main outcome of this debt is an increase in the financial cost of supplying goods. In some university hospitals the payback period can extend up to 2 years. In other words, the company can get the payment for the goods provided two years after provision. Under these conditions, the suppliers of goods increase the cost of goods in order Published by Sciedu Press to take the risks for late payment. This artificial increase in costs contributes to increasing debts of hospitals and lead to a vicious cycle.

In 2010-2011, the government has transferred additional funds to university hospitals to cover their debts and to decrease the costs of obtaining goods from companies. The total amount of these funds was around 420 million TRY. The figure below displays the trends in the most renowned university hospitals in Turkey.

As can be seen in Figure 4, the increasing debt trend has not changed in these pioneering university hospitals except the Hacettepe hospital. The reasons for this are explained below.

\section{CAN PROblems in Financing be OVER- COME WITH A DIFFERENT MANAGE- MENT APPROACH: AN EXAMPLE FROM HACETTEPE UNIVERSITY?}

Hacettepe University Hospital is among the most renowned university hospitals in Turkey with its high quality services and research capacity. Its high quality services are also accredited internationally by the Joint Commission International (JSI). The hospital complex is comprised of three hospitals and a satellite hospital: Adult Hospital (728 beds), Children's Hospital (261 beds), Oncology Hospital (135 beds), Beytepe Day Hospital (6 beds).

As stated earlier, in 2010 the government transferred resources to university hospitals in order to close their debts especially to the firms. Hacettepe University received 133 million TRY from this initiative. At the same time, the $\mathrm{MoH}$ transferred cash to hospitals in order to compensate for their losses after the full-time policy. This meant a cash flow of 182 million TRY in 2010 to Hacettepe University Hospital when its total debt was 166 million TRY. However, despite this cash flow, the debt of the hospital reached to over 260 million TRY in 2011. The figure below shows the debt flow of the hospital and flow of patients.

As clearly shown in Figure 5, the income and expenditure balance has dropped to negative after 2004 and a big deficit has occurred after that point. The hospital management at that time decided to close some beds with the belief that these beds were the main causes of this deficit as the real cost of the service was over the HIG prices. This was one of the most important mistakes made by the management. Closing beds and decreasing the income of the hospital is not a good option as the fixed costs continue to incur with or without beds. The hospital management, instead of closing beds and decreasing income, should have taken precautions to increase income and decrease costs in order to avoid accumulation of a huge debt. 


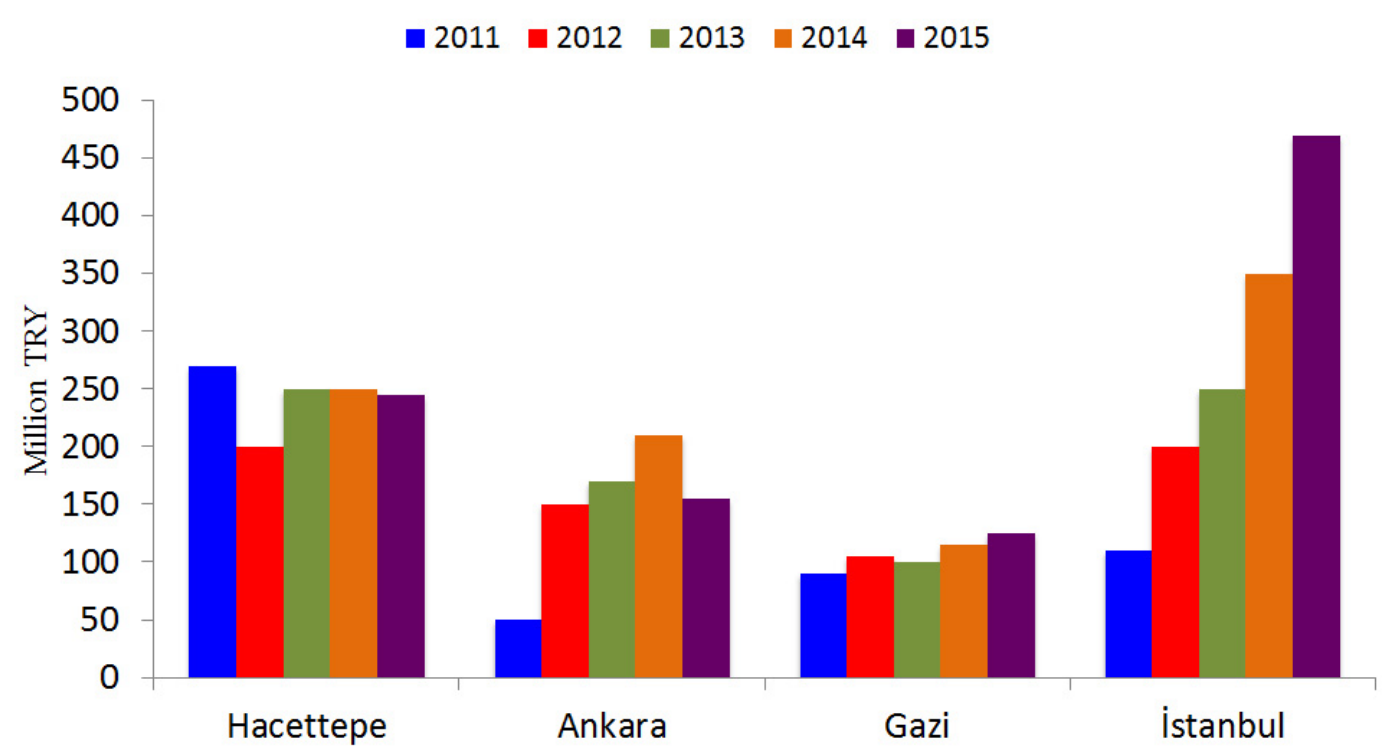

Figure 4. Change in revolving fund debts: Examples from four university hospitals

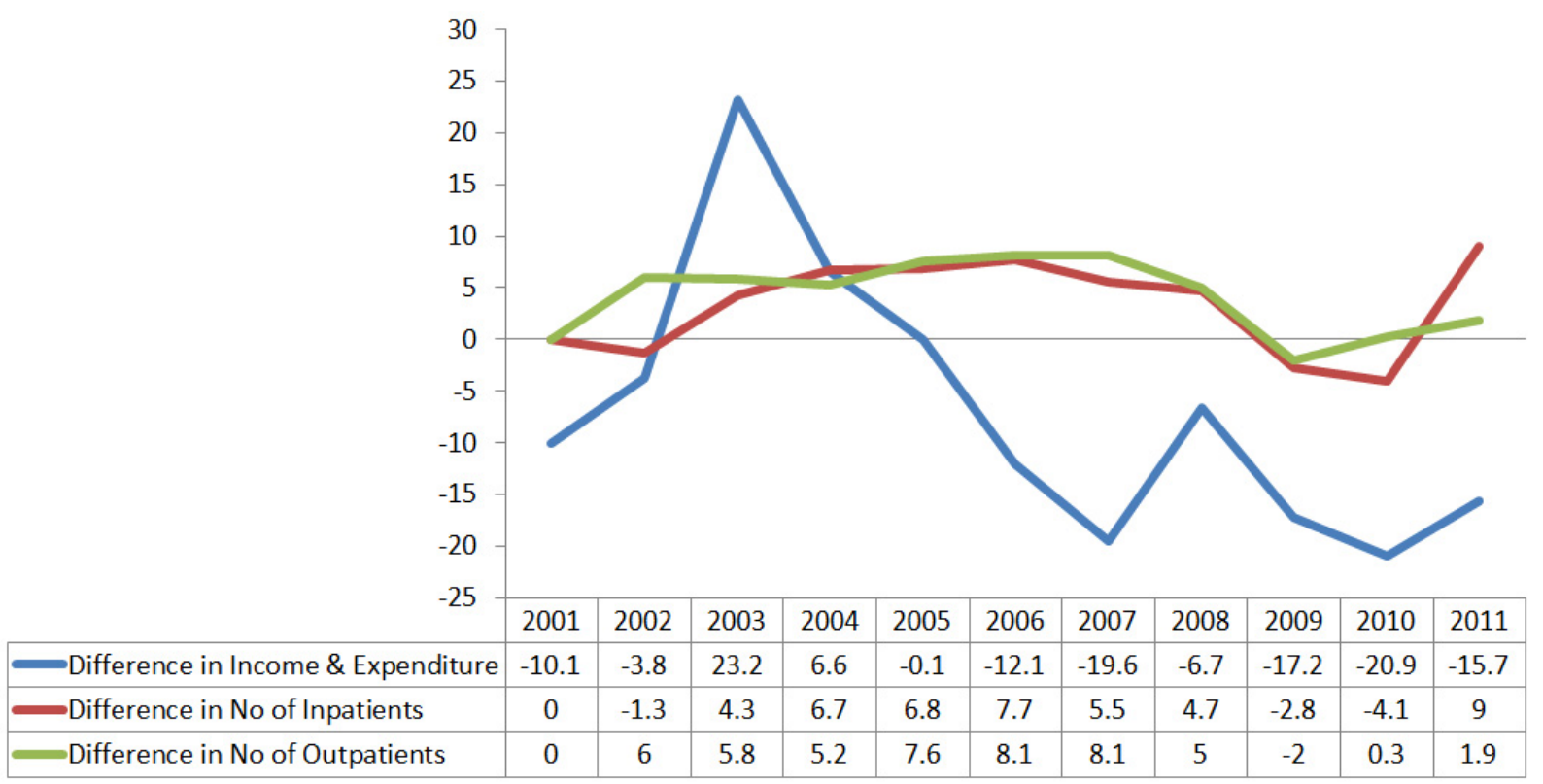

Figure 5. Debt flow of Hacettepe University Hospital

In December 2011 the management of the University and hence the hospital has changed and the mentality of the hospital management shifted from a management mainly focusing on preserving status quo to a problem solving management oriented towards making structural changes to overcome the huge debt crisis. These are outlined below:

\subsection{Reorganization of SSI procedures}

As stated earlier, the SSI is the main purchaser of health care services in Turkey. Hospitals send their bills to the SSI monthly and receive their funds based on the procedures completed. The SSI draws a sample of these bills and checks if there are any frauds, miscalculations and anything against the rules of HIG. The SSI, then, deducts this percentage of miscalculations from the overall total of the monthly bill of the hospital. If the percentage is high, this means that the hospital would receive less then its expected total amount and will not receive money for some services already provided. This percentage was very high for Hacettepe Hospital before December 2011 as there wasn't a system and trained staff to 
follow the HIG rules properly within the hospital. The rates were $29 \%$ and $27 \%$ in 2009 and 2010 respectively. The new management took this problem seriously and embarked on a series of measures including introduction of a new hospital information system and a new team of experts specially trained for following HIG rules. These measures showed their results immediately and the percentage of deductions decreased to $8 \%, 3 \%$ and $1.5 \%$ in 2012, 2013 and 2014 respectively. With the introduction of global budget in 2015 this deduction system was abandoned automatically.

\subsection{A new approach to purchasing goods}

One of the main problems approached by the new management was to introduce a new purchasing policy to control the incredibly high cost of purchasing especially medical goods and devices. As the hospital's debt was too high and as the payment period was too long (sometimes reaching to three years) the companies were selling goods with prices higher than their real values. This meant an artificial increase in the cost of buying goods and contributed to increasing debt of the hospital. The new management also, to overcome the sudden crisis of purchasing essential materials, purchased some goods through the MoH hospitals purchasing system so the prices went down to $\mathrm{MoH}$ prices. The table below displays the change in expenditures in certain items in the first year followed by a figure showing the impact of these measures on the unit costs of some laboratory tests.

As can be seen in Figure 6, the unit costs of laboratory tests were substantially decreased mainly because of new approaches in purchasing inputs for tests and also because of effective use of already available resources. This and similar measures in other areas have contributed to contain the ever increasing debt of the university hospital and also to a sustainable financial environment.

Table 1. Change in expenditures for certain items

\begin{tabular}{llll}
\hline Type of Expenditure & $\mathbf{2 0 1 1}$ & $\mathbf{2 0 1 2}$ & Change (\%) \\
\hline Laboratory goods and chemicals & $12,222,719$ & $11,459,820$ & -6 \\
Medical Devices & $38,506,291$ & $22,925,288$ & -41 \\
Pharmaceuticals & $15,335,984$ & $18,631,830$ & 22 \\
Cleaning goods & 707,132 & 577,094 & -19 \\
Stationary & 817,597 & 257,169 & -69 \\
Maintenance and repair & $5,419,084$ & $3,617,023$ & -33 \\
\hline Total & $73,008,807$ & $57,468,224$ & -21.3 \\
\hline
\end{tabular}
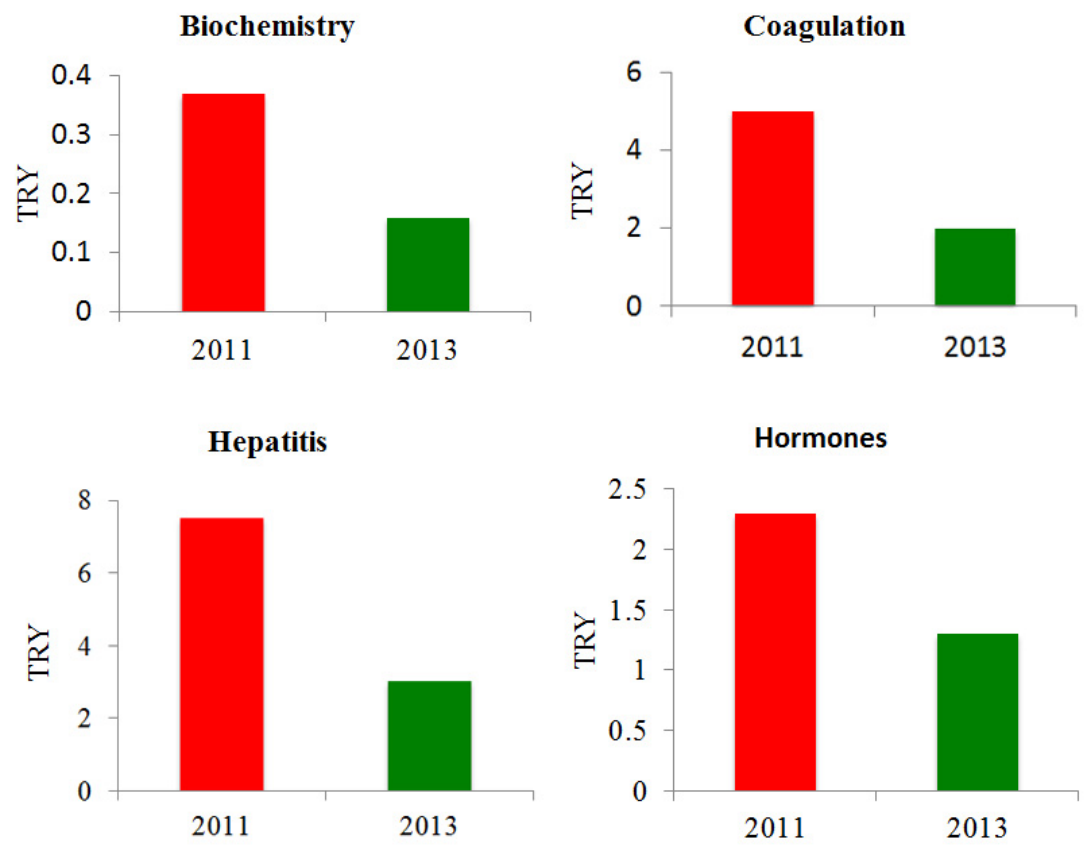

Figure 6. Unit costs of laboratory tests in a changing management environment 


\subsection{Increasing number of international patients}

International patients are a very good source of income for hospitals as they are exempt from the SSI rules and price regulations. Hacettepe University Hospital, despite its reputation for high quality health care services, have not benefited from this until 2012. A special unit responsible only for international patients was established to deal with these patients and a number of measures were taken to improve services. In 2011 there were only 8 international patients and these patients reached to 1,400 in 2015 .

\subsection{A new approach to rational use of beds}

Irrational use of available hospital beds has also contributed to mismanagement of hospital resources in the past. Previously beds were assigned to certain wards and only patients treated in a certain specialty could be hospitalized in those wards. This resulted in empty beds in certain wards but beds with long waiting queues in other wards. In addition to this, patients in the emergency department could not be hospitalized quickly if the beds in the related ward were full. The main challenge for changing this policy was the resistance of department heads who did not want to loose their power on patient allocation and use of beds. The new management changed these procedures so that the chief of medical director could use beds without the consent of department heads. This also contributed to the rational use of emergency department as well.

These measures have resulted in $9 \%$ efficiency increase in surgical wards, $6 \%$ efficiency increase in internal medicine wards and $23 \%$ efficiency increase in intensive care units.

\subsection{New approaches to materials management}

One of the problems of the old management was related to materials management, as there wasn't a system for following stocks and providing goods at the right time at the right place. This resulted in buying unnecessary goods that are already available in one department but experiencing scarcity for the same good in another department. A new stock management system, approaching the materials management issues with an integrated approach, was introduced to the hospital management system.

All these measures have resulted in remarkable increase in number of services provided which in the end contributed to containing the increasing costs and debts of the university hospital. The number of outpatients increased to 973,722 in 2014 from 838,260 in 2011 ( $16.2 \%$ increase), number of inpatients increased to 124,482 in 2014 from 76,731 in 2011 (62\% increase) and number of operations increased to 51,586 in 2014 from 31,861 in 2011 (62\% increase). As a result of these policies, the monthly net revenue of the revolving fund increased to 11 million USD in 2015 from 5 million USD in 2011.

The university hospital's management changed again at the beginning of 2016 and the same status-quo preserving approach was adapted. In Turkey the Rector of a university is elected by the academic staff every four years and is appointed by the President of the country. She/he has the ultimate power over the whole university, including the university hospital. The process is highly complicated and both national and university politics play an important role from the election of the Rector to his/her policies and actions. The vision, approach and knowledge of the Rector are the key elements in management of all university entities. She/he can change the whole management team of the university and can form a team of people reflecting his/her ideals and vision. All rectors of the Hacettepe University have been elected from the Faculty of Medicine in the past, reflecting the power of the Faculty over others. The main difference in approach between the two management terms (between 20112016 and 2016 until now) was the reformist vision of the former management team not only for the university hospital but also for the university as a whole. A more production and performance oriented approach; driven by efficiency and high quality were the main pillars of the former team and this of course challenged the status quo and sources of power that has ruled the university for over 40 years. The changes in the system meant working more and brought accountability principles to the whole staff, which was disliked by the highly influential political elite of the university. As a result, in the election the candidate, who promised to overturn new initiatives and to bring the university back to pre-2011 period, won the election. This was followed by replacing the whole management team of the university including the hospital managers. In sum, it could be stated that the underlying reasons for returning back to former policies that resulted in increasing debt for the hospital were internal politics and conflict of power within the institution.

A number of new policy initiatives from the former management were replaced with the old policies. As a result of this, at the end of 2016, the debt of Hacettepe University Hospital reached to 350 Million TRY again and the increasing trend continues. There are discussions around government circles to change the status of university hospitals into $\mathrm{MoH}$ hospitals.

\section{DisCuSSION AND CONCLUSIONS}

The financial status of university hospitals have long been on the agendas of Turkish policy-makers and is perceived as a major threat to the financial sustainability of the Turkish health care system. There are both intrinsic and extrinsic fac- 
tors contributing to the current financial crisis. Extrinsic factors are mainly related with the payment rules and policies of the SSI. However, as shown by the example from Hacettepe University Hospital, intrinsic factors can also have a substantial role in debt management. A management approach, prioritizing cost containment and efficiency has resulted in more financial resources for hospital staff, stabilization of debts and payment of company debts. This case proofs a need for adopting a different approach both at the macro and micro level to solve the problem. These are summarized below.

\subsection{Problems at the macro level}

(1) Misconceptions about the role of university hospitals at the macro level. The teaching and research status and mission of university hospitals are sometimes disregarded at the macro policy-making level. University hospitals, different from $\mathrm{MoH}$ tertiary hospitals provide medical education both at the graduate and undergraduate level. This requires a different approach in allocation of resources to these hospitals and also to reimbursement rules as well.

(2) Case complexity of university hospitals. A substantial proportion of a university hospital's case-mix is comprised of complex cases that cannot be treated at the secondary level and hence the cost of provision of these services is high. The SSI's payment rules and prices do not reflect the real cost of health care services and in reality there is no scientific evidence about the determinants of these prices. The HIG rules and prices do not change systematically to reflect the increases in cost of inputs and lag behind the real life costs.

\subsection{Problems at the micro level}

(1) Hospital managements oriented towards preserving the status quo. Introduction of new measures emphasizing cost containment and efficiency is not an easy option for management as these may also target the overall balance of power among hospital staff. Changing rules and practices inherited from previous managements can be a tough challenge especially in an organization with a highly complex professional staff.

(2) Introduction of new management concepts at the financial level. In organizations without efficiency and effectivenessoriented policies, introduction of these concepts is not easy for mainly two reasons. The first reason is related with the skepticism to change that is inherent in almost instances and the second is related with the lack of skill, knowledge and expertise to implement and monitor these policies.

Despite the problems summarized above, Hacettepe University example has proved that cost containment and debt

Published by Sciedu Press control can be achieved under current circumstances as well. Without changing the management approach at the micro level, any change at the macro level will lead to unsuccessful financial management, increasing cost burden and negatively motivated health care staff. That is why at the eve of changing the status of university hospitals, the policy-makers should also think about introduction of a new management approach at the micro level.

There are of course limitations of this study. First of all, the study is based on the financial performance indicators of a university hospital and analysis of available data. As such, the research methodology cannot be validated and cannot be replicated. Case based approach should be adopted for similar research in other university hospitals. Second, although Hacettepe University Teaching and Research Hospital has a pioneering role among all university hospitals, its case does not represent the whole university hospitals community. Third, the cost cutting measures chosen in this example were unique to Hacettepe University Hospital and as there is no literature on similar examples, if there are any, use and comparison of other studies could not be made.

As the last concluding remark it could be stated that there are initiatives to be taken both by the government and academia in order to overcome the financial burden of university hospitals on the whole health care system. The government should revise the reimbursement policies of the SSI and should explore opportunities to raise the resources devoted to these hospitals. Research and training missions of these hospitals should not be overlooked and separate government resources should be allocated for these functions. Hospitals are highly complex organizations requiring a specialized management approach and skills. The management team should be formed by skilled staff especially trained for hospital administration and should have enough experience to take the responsibility of these highly complex entities. The academics working in this area should focus on research that could be used both by the government and hospitals. There is a lack of interest from the academic environment to financing problems of the university hospitals. The first step may be introducing a costing approach to university hospitals based on real costs of providing services. The SSI should use the results of this research in its reimbursement policies. Last but by no means the least, rules of managerial accountability should be established and applied in university hospitals. At the moment neither the hospital managers, nor the Rector are kept responsible for increasing debts and mismanagement of hospitals. The current system is unsustainable for all university hospitals in Turkey.

\section{ACKNOWLEDGEMENTS}

The achievements summarized above are the outcome of the 
efforts of a dedicated team. We acknowledge the efforts of all staff who contributed to the achievements between December 2011-January 2016.

\section{CONFLICTS OF INTEREST Disclosure}

The authors declare they have no conflict of interest.

\section{REFERENCES}

[1] Ministry of Health. Health Statistics Yearbook. Ankara; 2015.

[2] Atun R, Aydın S, Chakraborty S, et al. Universal Health Coverage in Turkey: Enhancement of Equity. The Lancet. 2013; 382(9886) 65-99. https : //doi .org/10.1016/S0140-6736(13) 61051-X

[3] Lichtenberg F, Tatar M, Çalışkan Z. The effect of pharmaceutical innovation on longevity, hospitalization and medical expenditure in Turkey, 1999-2010. Health Policy. 2014; 117(3): 361-373. PMid:
24996837. https://doi.org/10.1016/j.healthpol.2014.0 6.002

[4] Lichtenberg F, Tatar M, Calıskan Z. The Impact of Innovation on Health Outcomes and Utilization in Turkey: a Re-Examination. Health Policy and Technology. 2017. https://doi.org/10.101 6/j.hlpt.2017.01.003

[5] Tatar M, Mollahaliloğlu S, Şahin B, et al. Turkey: Health system review. Health Systems in Transition. 2011; 13(6): 1-186. PMid: 22455830. 